\title{
Novel halogen-free flame retardant thermoset from a hybrid hexakis (methoxymethyl) melamine/phosphorus-containing epoxy resin cured with phenol formaldehyde novolac
}

\author{
Z. Z. Huang1, X. H. Zhang2*, G. R. Qi ${ }^{2}$ \\ ${ }^{1}$ The Department of Chemistry, Zhejiang University, Hangzhou 310027, China \\ ${ }^{2}$ Key Laboratory of Macromolecular Synthesis and Functionalization (Ministry of Education), Department of Polymer \\ Science and Engineering, Zhejiang University, Hangzhou 310027, China
}

Received 19 July 2009; accepted in revised form 12 September 2009

\begin{abstract}
This paper describes the curing behaviours, thermal properties and flame-resistance of a novel halogen-free epoxy hybrid thermoset, prepared by the curing reaction of hexakis (methoxymethyl) melamine (HMMM), a phosphorouscontaining epoxy resin (EPN-D) with 9, 10-dihydro-9-oxa-10-phosphaphenanthrene 10-oxide (DOPO) group and phenol formaldehyde novolac (n-PF). The resultant thermosets showed high glass-transition temperatures $\left(T_{g}, 123-147^{\circ} \mathrm{C}\right)$ as determined by thermal mechanical analysis (TMA), excellent thermal stability with high $5 \mathrm{wt} \%$ decomposition temperatures $\left(T_{d, 5 \%} \geq 308^{\circ} \mathrm{C}\right)$ and high char yields $\left(Y_{c} \geq 39.4 \mathrm{wt} \%\right)$ from the thermogravimetric analysis (TGA). All the cured EPN$\mathrm{D} / \mathrm{HMMM} / \mathrm{n}-\mathrm{PF}$ hybrid resins achieved the UL $94 \mathrm{~V}-0$ grade with high limited oxygen indices (LOI > 45.7). It is found that phosphorous and nitrogen elements in the cured EPN-D/HMMM/n-PF hybrid resins had a positive synergistic effect on the improvement of the flame retardancy.
\end{abstract}

Keywords: thermosetting resins, thermal properties, flame retardancy, epoxy

\section{Introduction}

Epoxy resins are widely used as functional materials due to their superior thermo-mechanical properties and excellent processability. However, the flammability limits the usage of epoxy resins in the field of electrical/electronic substrates. Halogen is usually applied to improve the flame retardancy of the epoxy resins. Nevertheless, halogen-containing epoxy resins have a series of potential environmental issues during decomposition or incineration $[1,2]$. Halogen-free flame-retardant epoxy resins [3-30] are being developed and are expected to reduce the release of toxic substances during fire. By covalent incorporation of nitrogen $[11,12$, 15-24] and phosphorous $[3,4,7-9,13,14,22,23$, $26,30]$ into the backbone of the epoxy resins, better flame retardancy can be achieved. Thereinto, it is a very effective way to improve the flame retardancy by introducing $\mathrm{P}$ and $\mathrm{N}$ elements together into the epoxy matrix. For example, the incorporation of a thermal-stable cyclic phosphinate, i.e.: 9, 10dihydro-9-oxa-10-phosphaphenanthrene 10-oxide (DOPO) [3] in combination with an isocyanurate structure [15-18], or a triazine structure [11, 14, and 20] into an epoxy matrix led to excellent flame retardancy without losing heat resistance. In these $\mathrm{P}$ and $\mathrm{N}$ containing flame retardant systems, $\mathrm{P}$ is favourable to the formation of char structure while $\mathrm{N}$ is generally released as a non-flammable gas which can dilute air and absorb heat energy in combustion. However, complex synthesis of most 
reported nitrogen-containing epoxy resins or hardeners $[19,21]$ is unfavourable to their application. Hexakis (alkoxymethyl) melamine (HMMM) is widely used as flame retardant for polymeric materials because it has high nitrogen content and low cost. It has also been applied to blend with epoxy resin for preparing halogen-free flame-retardant epoxy thermoset $[11,12,23]$. However, it is better to avoid serious phase separation between the HMMM network and epoxy network for the epoxy/HMMM/hardener system during cure. It was reported that silane coupling agents could be used to increase the miscibility of the epoxy network and the HMMM network for the epoxy/HMMM/ diamine system [11]. Very recently, an epoxy/phenol formaldehyde novolac resin (n-PF) curing system was developed for preparing nitrogencontaining epoxy hybrid thermoset without using silane coupling agents, on the basis of reaction of HMMM and n-PF. However, there is still one problem for this hybrid system when it was used as electrical/electronic substrates. That is, HMMM alone is not enough to improve the flame resistance. In the present work, a phosphorous-containing epoxy resin (EPN-D), which was synthesized via the addition reaction of DOPO and epoxy phenol formaldehyde novolac resin (EPN) [22], was blended with HMMM and used for preparing a halogen-free flame-retardant epoxy resin. The curing behaviours, thermal properties and flame retardancy of the resultant thermosets were investigated in detail.

\section{Materials and methods}

Hexakis (methoxymethyl) melamine (HMMM, density: $1.2 \mathrm{~g} / \mathrm{ml}$, viscosity: $3000-6000 \mathrm{mPa} \cdot \mathrm{s}$

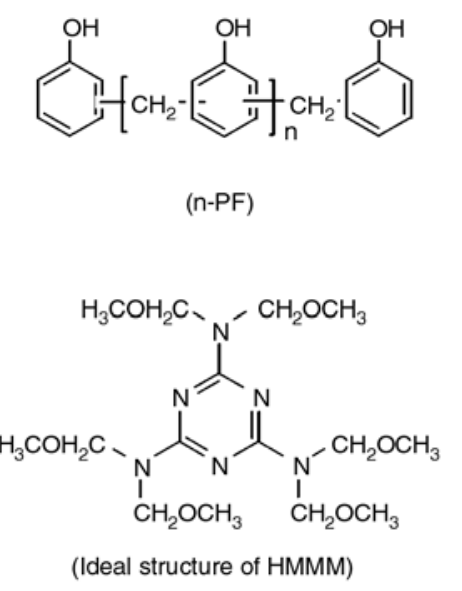

Figure 1. Chemical structures of n-PF, EPN-D and HMMM $\left(25^{\circ} \mathrm{C}\right)$, heat loss $<2 \mathrm{wt} \%$ at $105^{\circ} \mathrm{C}$ for $1.5 \mathrm{~h}$, free formaldehyde: $\leq 0.5 \mathrm{wt} \%$, degree of polymerization: 1.75) was obtained from Xinhua Chemical Co. (Hangzhou, China). Phenol formaldehyde novolac resin (n-PF, softening point: $85-95^{\circ} \mathrm{C}$, free phenol $\leq 0.1 \mathrm{wt} \%$,) was granted kindly from KingBoard Chemical Co., Ltd. (Kunshan, China). Epoxy phenol formaldehyde novolac resin (EPN, functionality $=4-6$ ) with EEW $182 \mathrm{~g} / \mathrm{eq}$ was purchased from Shanghai Resin Company (Shanghai, China). 9, 10-dihydro-9-oxa-10-phosphaphenanthrene 10-oxide (DOPO) was supplied kindly by Hang Zhou JLS Flame Retardant Co., Ltd. (Hangzhou, China) and used as received. 4,4'diaminodiphenylmethane (DDM) and 4,4'-diaminodiphenyl sulphone (DDS) were purchased from Sinopharm Chemical Reagent (Shanghai, China) and used without purification. Phosphorus-containing epoxy resin (EPN-D) was synthesized from the addition reaction of DOPO and EPN according to the reported method [22]. The structures of n-PF, HMMM and EPN-D are shown in Figure 1. $P$-toluenesulfonic acid ( $p$-TSA) was purchased from Sinopharm Chemical Reagent Co., Ltd. (Shanghai, China) and used as a catalyst.

Differential scanning calorimeter (DSC) measurements were performed on a Perkins-Elmer DSC 7 thermal analyzer at a heating rate of $10^{\circ} \mathrm{C} / \mathrm{min}$ under $\mathrm{N}_{2}$. Gel Time Tester GT-2 was used to determinate the gel time of resins according to IPC-TM650 method, which is an industrial method for evaluating the gel time of a resin. $T_{g}$ data of the thermosets were obtained from the measurement of DSC at a heating rate of $20^{\circ} \mathrm{C} / \mathrm{min}$ under $\mathrm{N}_{2}$ atmosphere. Thermogravimetric analyses (TGA) were carried out on a Perkins-Elmer Pyris 1 under an $\mathrm{N}_{2}$

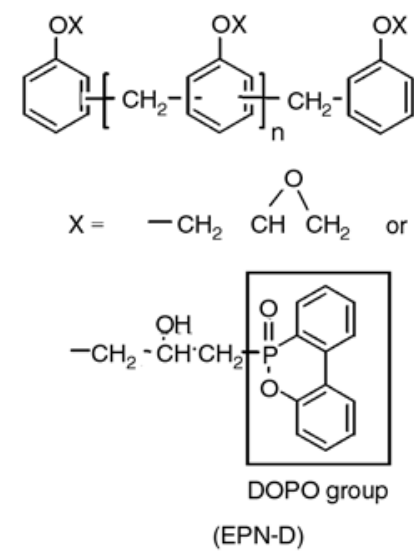


atmosphere at a heating rate of $10^{\circ} \mathrm{C} / \mathrm{min}$ from 50 to $850^{\circ} \mathrm{C}$. Limited oxygen indices (LOI) were measured on a HC-2 LOI tester according to ASTM D-2863-77. The percentage in the $\mathrm{O}_{2}-\mathrm{N}_{2}$ mixture deemed sufficient to sustain the flame was taken as the LOI. The UL-94 vertical test was performed according to the testing method proposed by Underwriter Laboratories Inc. with the test specimen bars of $130 \mathrm{~mm}$ in length, $13 \mathrm{~mm}$ in width and $1.6 \mathrm{~mm}$ in thickness. During the test, five sample bars suspended vertically over surgical cotton were ignited by a Bunsen burner. A flame was applied twice to the lower end of the bar for $10 \mathrm{~s}$. The ratings of $\mathrm{V}-0, \mathrm{~V}-1$ were achieved if burning stops within 10, $30 \mathrm{~s}$ after two applications of $10 \mathrm{~s}$ each of a flame to a test bar, and no flaming drips were allowed. The $\mathrm{Z}$-axis coefficient of thermal expansion (Z-CTE) was measured with a DuPont 943 thermal mechanical analyzer (TMA) in accordance with ASTM E83-186. A specimen of $4 \mathrm{~mm}$ long, $4 \mathrm{~mm}$ in wide and $1.6 \mathrm{~mm}$ in thick was measured at a heating rate of $5^{\circ} \mathrm{C} / \mathrm{min}$. Normally the thermal expansion increases with increasing of the temperature and the CTEs are calculated from the slope. An abrupt change in slope of the expansion curve indicates a transition of the material from one state to another. $\alpha_{1}$ and $\alpha_{2}$ are the CTE values below and above $T_{g}$ respectively.

\section{Preparation of the epoxy thermosets}

The preparation of EPN-D/HMMM (10)/n-PF resin (i.e. with $10 \mathrm{wt} \% \mathrm{HMMM}$ in the EPN-D/n-PF resin) is described next as an example. HMMM $(12 \mathrm{~g})$ and deionized water $(1.2 \mathrm{~g})$ were dissolved in butanone $(50 \mathrm{ml})$, and the solution was stirred at room temperature. After the addition of $p$-TSA $(0.12 \mathrm{~g})$, the solution was stirred at $60^{\circ} \mathrm{C}$ for $1 \mathrm{~h}$ to yield homogeneous solution A. EPN-D (80 g) and of n-PF (28 g) were dissolved in $100 \mathrm{ml}$ of butanone, and the solution was stirred at room temperature for $1 \mathrm{~h}$ to obtain homogeneous solution $\mathrm{B}$. Solutions A and B were then poured together in a beaker and stirred at $60^{\circ} \mathrm{C}$ for another $1 \mathrm{~h}$. A viscous, homogeneous solution was obtained, which was then poured onto a stainless plate and treated at $60^{\circ} \mathrm{C}$ in vacuo for complete removal of all volatiles. The obtained thermoset was transparent. All the epoxy thermosets were prepared with the curing procedure of $120^{\circ} \mathrm{C}(1 \mathrm{~h}), 160^{\circ} \mathrm{C}(2 \mathrm{~h})$ and $190^{\circ} \mathrm{C}$
(2 h). For comparison, the sample preparation method was applied for EPN-D/HMMM/DDS (and DDM) curing system, DDS and DDM were mixed with EPN-D at an equivalent molar ratio of $1: 1$ respectively.

\section{Results and discussion}

\subsection{Preparation and curing process of EPN-D/HMMM resin with various hardeners}

It is known that novolac phenol formaldehyde resin (n-PF) is a hardener for preparing high-performance epoxy materials. It has strong reactivity towards HMMM and hydrated HMMM [23, 31]. It was reported that the usage of n-PF could avoid the phase separation between the HMMM network and epoxy network of the resultant materials [23]. Herein, aimed to prepare a new halogen-free epoxy material with excellent flame retardancy, n-PF was chosen and cured with HMMM and a phosphorouscontaining epoxy resin (EPN-D, Figure 1) [22]. In the process for making such EPN-D/HMMM/nPF hybrid resin (depicted in Figure 2), HMMM should be partly hydrated by quantitative water using $p$-TSA $(\sim 0.1 \mathrm{wt} \%)$ as a catalyst at first to generate a (hydroxymethyl) melamine [23]. This is a very important step for that (hydroxymethyl) melamine is more reactive than HMMM in the blend, and hydroxyl groups are favourable to condensation of HMMM [11]. The hydrated HMMM was then dissolved into solution B (here, DDS and DDM were used as hardeners for control experiments). After complete removal of all volatiles from the mixture, a transparent resin was obtained. It was disclosed that an epoxy/HMMM/hardener hybrid resin contained at least two reactions when heating them [11, 23]. One was the HMMM condensation with an endothermic process, and the other was the epoxy/hardener addition polymerization with an exothermal process. So the curing behaviours of EPN-D/HMMM/hardeners (n-PF, DDS and DDM) resins could be easily monitored by DSC method.

Figure 3 shows the DSC thermograms of the EPND/n-PF (DDS, DDM) resins and EPN-D/n-PF (DDS, DDM) resins with $20 \mathrm{wt} \%$ HMMM. One can see that the onset reaction temperature of the EPN-D/n-PF resin is $\sim 150^{\circ} \mathrm{C}$ (line 3, Figure 3) and lower than that of the HMMM condensation in the 

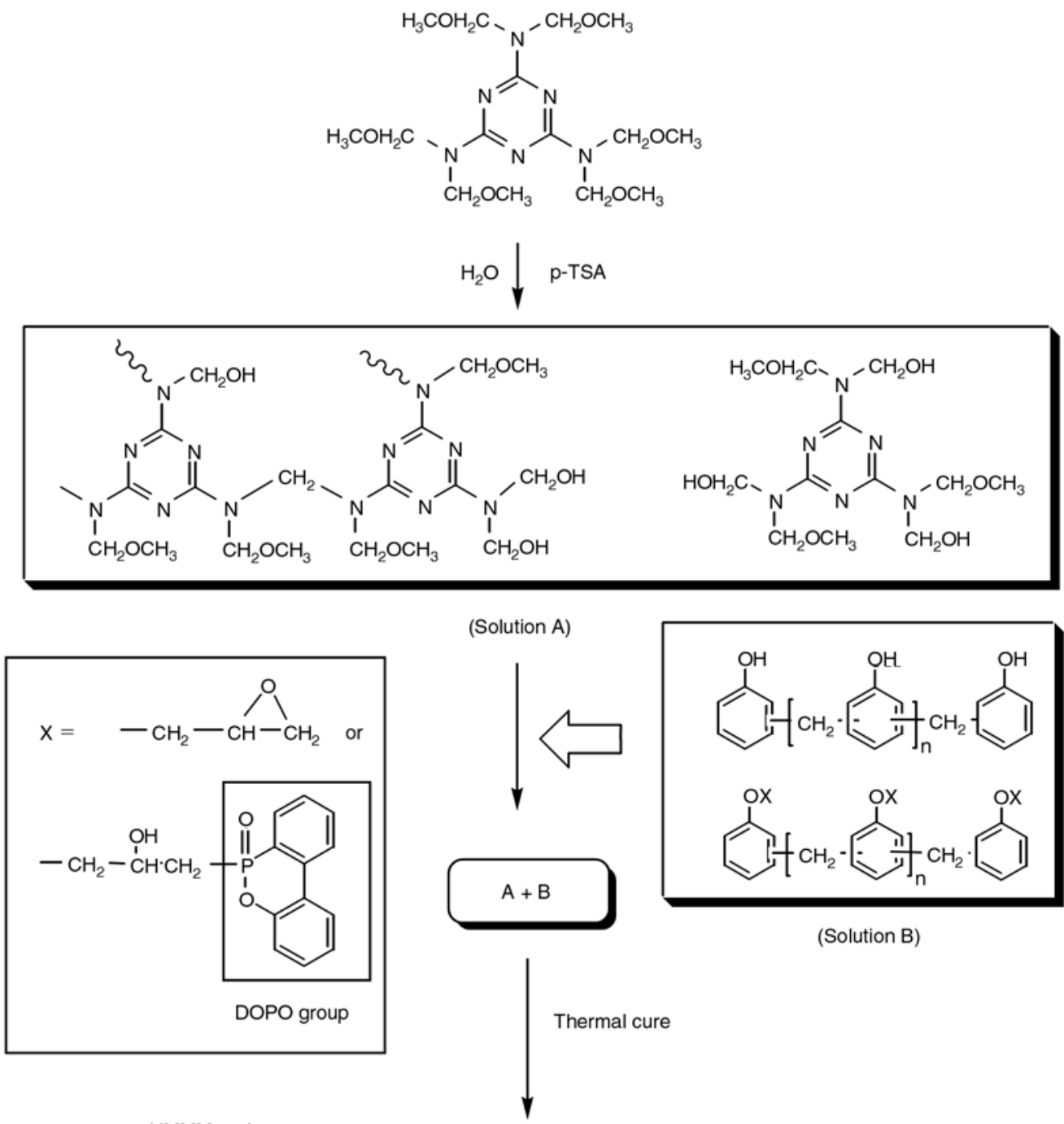

(Solution B)

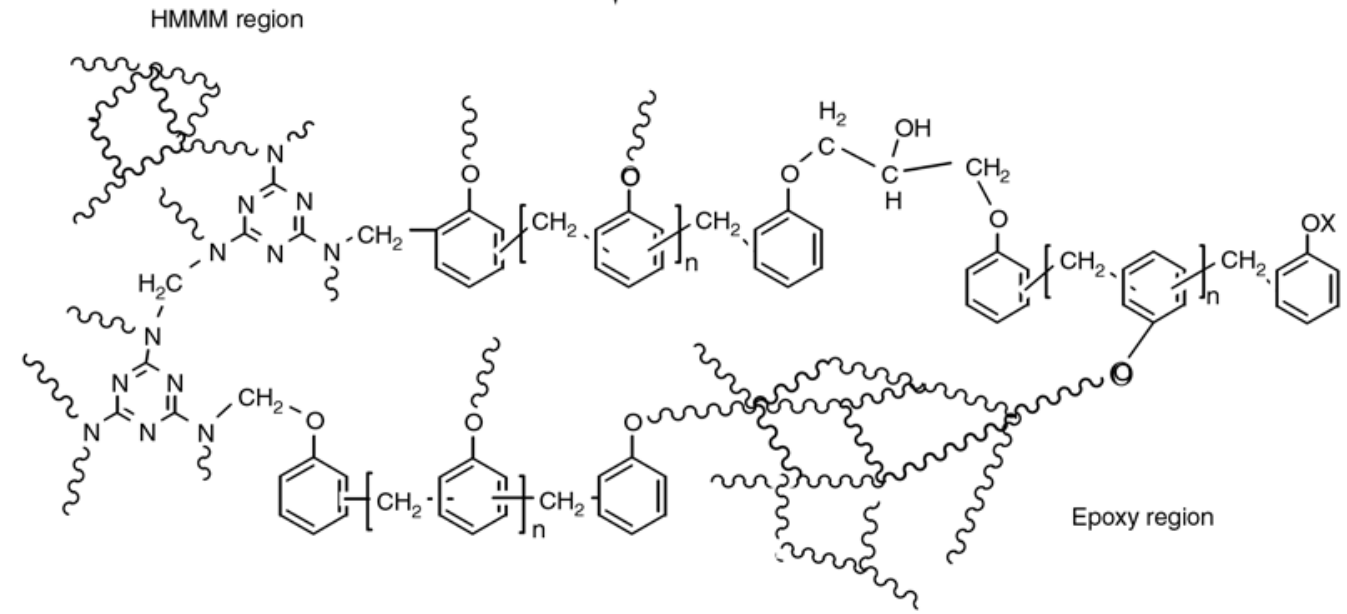

Figure 2. Scheme of the preparation and the curing process of the EPN-D/HMMM/n-PF hybrid resin

presence of $p$-TSA $\left(\sim 100^{\circ} \mathrm{C}\right.$ [23]). That is, the HMMM condensation occurred before the curing reaction of EPN-D/n-PF. Moreover, the exothermal temperature at which the maximum conversion rate occurs in the DSC curve $\left(T_{p}\right)$ of the EPN-D/ $\mathrm{HMMM} / \mathrm{n}-\mathrm{PF}$ resin is $211.5^{\circ} \mathrm{C}$ and slightly higher than that of EPN-D/n-PF resin $\left(201.4^{\circ} \mathrm{C}\right)$. This indicates that the curing reaction of EPN-D and nPF was not seriously retarded by the HMMM network. Because n-PF could react with HMMM in the blend, a macromolecular hardener containing triazine and hydroxyl groups could be produced. The generated HMMM network linked n-PF could also act as a hardener for EPN-D. Thus, the direct 


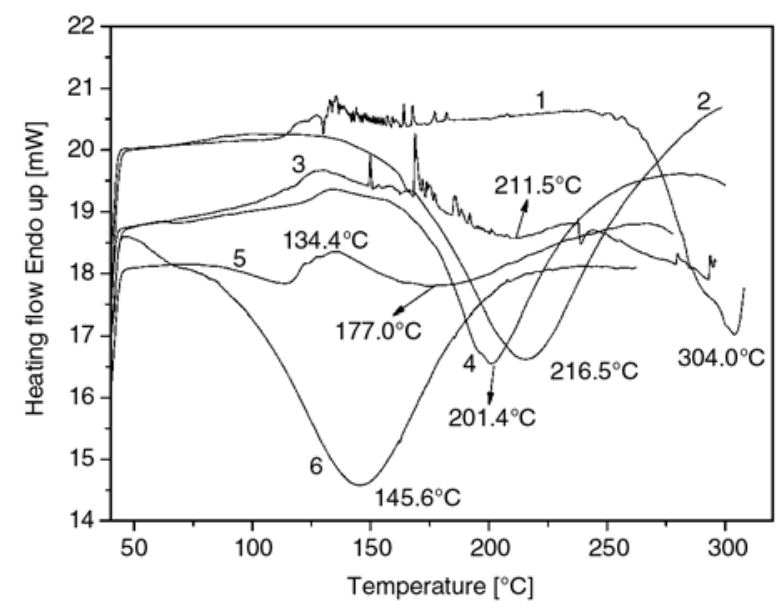

Figure 3. DSC thermograms of various epoxy samples at a heating rate of $10^{\circ} \mathrm{C} / \mathrm{min}$ under $\mathrm{N}_{2}: 1$. EPN-D/ HMMM (20)/DDS, 2. EPN-D/DDS, 3. EPN-D/ HMMM (20)/n-PF, 4. EPN-D/n-PF, 5. EPN-D/ HMMM (20)/DDM, and 6. EPN-D/DDM

linkages between HMMM (and n-PF) region and EPN-D/n-PF region could be built with increasing the temperature (illustrated in Figure 2). This may strengthen the thermal properties of the resultant thermosets in comparison with the cured EPN-D/nPF resin.

From curve 1 in Figure 3, it is seen that $T_{p}$ of the EPN-D/HMMM (20)/DDS resin is $304.0^{\circ} \mathrm{C}$ and dramatically higher than that of the EPN-D/DDS resin $\left(216.5^{\circ} \mathrm{C}\right)$. This indicates that the curing reaction of EPN-D and DDS in the resin was really retarded seriously by the HMMM network formed before (irregular endothermic peaks in the range of $110-200^{\circ} \mathrm{C}$ in curve 1 ) due to relative low reactivity of DDS to EPN-D resin. This would result in incomplete cure of EPN-D/DDS. In practice, it was observed that the resultant thermosets showed serious phase separation even if silane coupling agents used in the EPN-D/HMMM/DDS curing system. For the EPN-D/HMMM/DDM resin (curve 5 in Figure 3), it is found that $T_{p}$ is $177.0^{\circ} \mathrm{C}$ and higher than that of EPN-D/DDM resin $\left(145.6^{\circ} \mathrm{C}\right)$, and the endothermic peak is $\sim 134.4^{\circ} \mathrm{C}$ and in the range of the exothermal peak of the EPN-D/DDM resin. Presumably, the epoxy network was firstly formed before the formation of HMMM network (curve 5 in Figure 3), and so some HMMM remained in the thermoset. This would result in the deterioration of the thermal properties of the resultant thermoset. Moreover, this hybrid resin had a very fast curing rate (the gel time was less $20 \mathrm{~s}$ at $160^{\circ} \mathrm{C}$, determined according to IPC-TM-650 method) which is out of control in processing and is against practical application. However, the gel time of the EPND/HMMM (20)/n-PF resin was $\sim 300 \mathrm{~s}$ at $160^{\circ} \mathrm{C}$ which is accepted in practice.

\subsection{The glass transition temperatures $\left(T_{g} s\right)$}

The glass transition temperatures $\left(T_{g} \mathrm{~s}\right)$ for all the cured resins were obtained from DSC thermogram (see Figure 4) and TMA method. It is found that $T_{g}$ of the EPN-D/DDS thermoset $\left(156^{\circ} \mathrm{C}\right.$, curve 2$)$ is higher than that of the EPN-D/HMMM (20)/DDS thermoset $\left(126^{\circ} \mathrm{C}\right.$, curve 1$)$. It was also found that the second DSC heating curve of this thermoset showed a small exothermal peak beyond $200^{\circ} \mathrm{C}$. So it is clear that the epoxy network in this hybrid resin is limited by the HMMM network formed in advance, which resulted in the dramatic decrease of $T_{g}$ of the resultant thermoset.

The $T_{g}$ of the EPN-D/HMMM (20)/n-PF thermoset is $122^{\circ} \mathrm{C}$ (curve 3 in Figure 4) and higher than that of the EPN-D/n-PF thermoset $\left(111^{\circ} \mathrm{C}\right.$, curve 4$)$. Due to the strong reactivity of n-PF to HMMM and EPN-D in the curing process, the epoxy network and HMMM network were gradually 'buttoned' together tightly. Part of the rigid triazine moieties, which are hindered in free rotation and vibration, were copolymerized with EPN-D and n-PF. This would lead to the inhibition of the chain motion of the EPN-D/n-PF network by the formation of HMMM network (and HMMM/n-PF network) and cause the increase of $T_{g}$. For this hybrid resin, more amounts of HMMM may increase the chances of

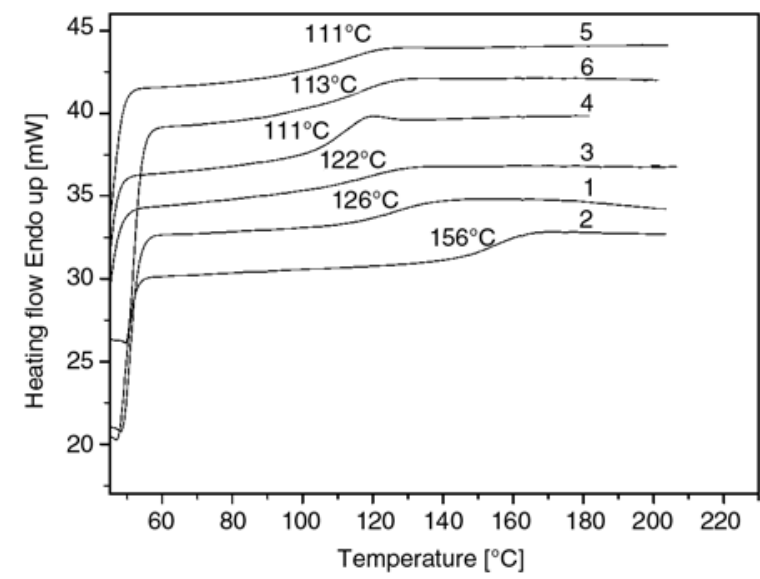

Figure 4. DSC curves of the cured samples: 1. EPN-D/ HMMM (20)/DDS, 2. EPN-D/DDS, 3. EPN-D/ HMMM (20)/n-PF, 4. EPN-D/n-PF, 5. EPN-D/ HMMM (20)/DDM, and 6. EPN-D/DDM 
condensation and thus decrease the residue of unreacted HMMM in the resultant thermoset. It is proved by the fact that $T_{g}$ s of the EPN-D/HMMM/ n-PF thermosets with $0,10,20$ and $30 \mathrm{wt} \%$ HMMM was $120,123,136$ and $147^{\circ} \mathrm{C}$ respectively, which were determined by TMA (Table 1). Although it is considered that the methoxymethyl group of HMMM can react with the amino group [32] of DDM, $T_{g}$ of the EPN-D/HMMM (20)/DDM thermoset is $111^{\circ} \mathrm{C}$ (curve 5, Figure 4) and is almost the same as that of the cured EPN-D/DDM resin $\left(113^{\circ} \mathrm{C}\right.$, curve 6 , Figure 4$)$. It is clear that the incorporation of HMMM into EPN-D/DDM resin couldn't increase the $T_{g}$ of the resultant thermoset.

\subsection{TGA evaluation}

The thermal stability and thermal degradation patterns of the cured EPN-D/HMMM/n-PF resins with various HMMM content were evaluated by TGA. Figure 5 shows the TGA curves of these thermosets. The thermal parameters including $5 \mathrm{wt} \%$ decomposition temperature $\left(T_{d, 5 \%}\right)$ and char yield $\left(Y_{c}\right)$ of these thermosets are collected in Table 1. It

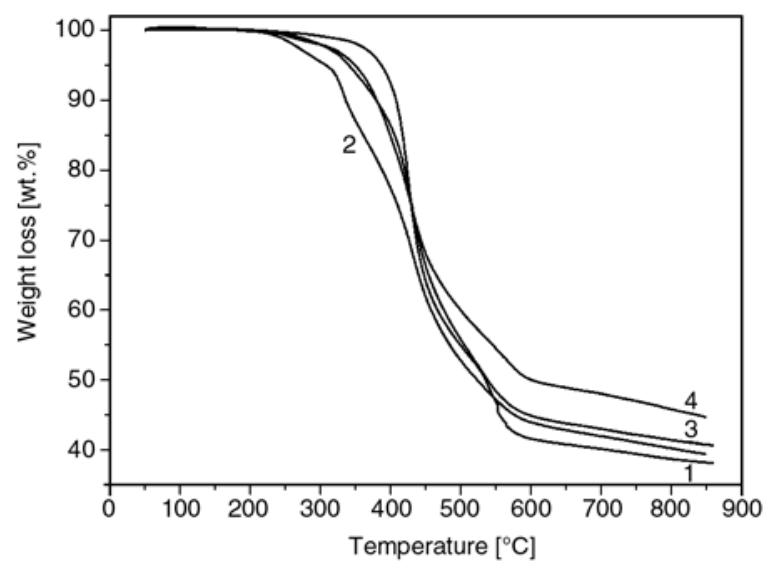

Figure 5. TGA curves of the EPN-D/HMMM/n-PF thermosets with: Line-1, 0 wt \%; Line-2, 10 wt $\%$; Line-3, 20 wt $\%$ and Line-4, 30 wt\% HMMM $\left(10^{\circ} \mathrm{C} / \mathrm{min}, \mathrm{N}_{2}\right)$ is found that $T_{d, 5 \%}$ of the EPN-D/HMMM/n-PF thermoset increased from 308 to $351{ }^{\circ} \mathrm{C}$ with increasing the content of HMMM from 10 to $30 \mathrm{wt} \%$. Such $T_{d, 5 \%}$ values are satisfactory for using as electric materials, however, they are clearly lower than that of the EPN-D/n-PF thermoset $\left(388^{\circ} \mathrm{C}\right)$. This may be attributed to the decomposition of the weak crosslink points between the triazine ring and some unreacted groups (e.g.: $-\mathrm{NCH}_{2} \mathrm{OCH}_{3},-\mathrm{NCH}_{2} \mathrm{OH}$ and $-\mathrm{NCH}_{2} \mathrm{OCH}_{2} \mathrm{~N}-$ etc.) in the HMMM network. For this hybrid resin, the probability of producing the weak linkages and unreacted groups may be decreased with increasing the HMMM content because the chance of the condensation of HMMM and n-PF/HMMM would be increased with increasing HMMM content when relatively more HMMM is applied. The char residue of the thermosets changes from 39.4 to $44.7 \mathrm{wt} \%$ when the HMMM content increases from 10 to $30 \mathrm{wt} \%$. It is considered that high crosslink density may be favourable to improving the char residue of the resultant thermosets, which was proved by TMA data in Table 1. The high char yields of these thermosets are favourable to form intumescent charred layers during fire and can block the spread of the fire, and thus ensure poor flammability. This will be proved by the following UL 94 vertical test results.

\subsection{Flame retardancy of the cured EPN-D/HMMM/n-PF resin}

Limited oxygen index (LOI) presents the minimum oxygen concentration (in a flowing mixture of oxygen-nitrogen gas) required to support candle-like downward flame combustion [3]. A material with LOI of 26 or higher is rated as a flame-retardant material [33]. It is strongly dependent on the char residue for halogen-free polymers and is suitable as a semi-qualitative indicator of the effectiveness of

Table 1. Thermal properties, flame retardancy and CTEs of the EPN-D/HMMM/n-PF thermosets ${ }^{\mathrm{a}}$

\begin{tabular}{|c|c|c|c|c|c|c|c|c|c|}
\hline $\begin{array}{c}\text { HMMM } \\
\text { content } \\
{[w t \%]}\end{array}$ & $\begin{array}{c}\mathbf{N} \\
{[w t \%]}\end{array}$ & $\begin{array}{c}\mathbf{P} \\
{[w t \%]}\end{array}$ & $\begin{array}{l}\mathbf{T}_{\mathbf{g}}\left[{ }^{\circ} \mathbf{C}\right] \\
\text { (TMA) }\end{array}$ & $\begin{array}{c}\text { CTE } \\
\left(\alpha_{1} / \alpha_{2}\right)\end{array}$ & $\begin{array}{c}\mathbf{T}_{\mathbf{d}, 5 \mathrm{wt}} \% \\
{\left[{ }^{\circ} \mathbf{C}\right]}\end{array}$ & $\begin{array}{c}\mathbf{Y}_{\mathbf{c}, \mathrm{wt} \%} \\
\left(\mathbf{8 5 0}^{\circ} \mathrm{C}\right)\end{array}$ & LOI & $\begin{array}{c}\text { Burning } \\
\text { time }^{b}\end{array}$ & $\begin{array}{c}\text { Classifica- } \\
\text { tion }\end{array}$ \\
\hline 0 & 0.00 & 2.50 & 120 & $51 / 280$ & 388 & 38.2 & 40.8 & 11 & V-1 \\
\hline 10 & 2.15 & 1.67 & 123 & $27 / 165$ & 308 & 39.4 & 45.7 & 7 & V-0 \\
\hline 20 & 4.30 & 1.48 & 136 & $34 / 163$ & 340 & 40.7 & 48.9 & 6 & $\mathrm{~V}-0$ \\
\hline 30 & 6.45 & 1.30 & 147 & $24 / 114$ & 351 & 44.7 & 55.5 & 5 & $\mathrm{~V}-0$ \\
\hline
\end{tabular}

athe curing procedure: $170^{\circ} \mathrm{C} / 2 \mathrm{~h}$ in a heat press with a pressure of $10 \mathrm{MPa}$ (without postcure procedure);

bthe maximum burning time after $10 \mathrm{~s}$ ignition for each test bar, no drippings 
the flame retardants in laboratory. While UL-94 vertical test is another testing method for flameretardancy evaluation of materials in industrial application with strong heat input, and thus the results depend on the integrated effects of all flameretardant elements the material contained.

The flammability of the thermosets was evaluated with their LOIs and by UL 94 test. Because of much higher concentration of phenol formaldehyde structures and high phosphorus content (2.5 wt $\%)$, which facilitated the formation of intumescent charred layers observed after ignition, LOI value of the EPN-D/n-PF thermoset is 40.8 and higher than that of the common epoxy thermoset (e.g.: LOI of the cured DGEBA/ethylenediamine resin is 19 [27]). The maximum burning time after $10 \mathrm{~s}$ ignition for the EPN-D/n-PF thermoset was $11 \mathrm{~s}$ and only achieved UL-94 V-1 grade. The main reason may be that the EPN-D/n-PF thermoset lacks nonflammable gas source in combustion to retard flame since it does not contain nitrogen element. The LOIs of the EPN-D/HMMM/n-PF thermosets containing 10, 20 and $30 \mathrm{wt} \%$ HMMM are 45.7, 48.9 and 55.5 respectively. The improvement of weight percentage of phosphorous and nitrogen elements in the thermoset with respect to the nonflammability of the epoxy thermoset is remarkable in comparison with the EPN-D/n-PF thermoset.

The UL-94 test results show that all EPN-D/ HMMM/n-PF thermosets can achieve UL-94 V-0 grade without any drippings. The maximum burning time after $10 \mathrm{~s}$ ignition for the thermosets containing 10, 20 and $30 \mathrm{wt} \%$ HMMM content are 7, 6 and $5 \mathrm{~s}$ respectively (see Table 1 ). For these halogen-free resins, the function of phosphorous in the materials is favourable to the formation of char residue (a solid phase flame-retardancy mechanism), whereas nitrogen can mainly be released as a non-flammable gas which can dilute air and absorb heat energy in combustion (a vapour phase flameretardancy mechanism). Herein, incorporating about $1.67 \mathrm{wt} \%$ of phosphorus and $2.15 \mathrm{wt} \%$ nitrogen element into the thermoset can make the thermoset flame-retardant in industrial applications, similarly to the XT/EPN-D/DICY system [22] reported by us earlier.

\subsection{Z-axis Coefficient of thermal expansion (CTE)}

The Z-axis coefficient of thermal expansion (CTE, $\alpha_{1} / \alpha_{2}$ ) of a polymer is a very important parameters for evaluating the long term stability and reliability of an electrical/electronic substrate. The lower the $\alpha_{1} / \alpha_{2}$ is, the better the dimensional stability of the thermoset is. It can be determined by TMA. The CTE values of the aforementioned EPN-D/ HMMM/n-PF thermosets are shown in Table 1. The $\alpha_{1} / \alpha_{2}$ of the EPN-D/n-PF thermoset was $51 / 280$ and bigger than that of all the EPN-D/ $\mathrm{HMMM} / \mathrm{n}-\mathrm{PF}$ thermosets in which the $\alpha_{1} / \alpha_{2}$ values decreased with increasing the HMMM content of the thermoset. This may be the result of the increasing crosslinking density, which is proved by the fact that $T_{g}$ s of the thermosets increased from 120 to $147^{\circ} \mathrm{C}$ with increasing $\mathrm{HMMM}$ content from 0 to $30 \mathrm{wt} \%$. These rigid triazine moieties may decrease the free volume of the thermoset, and thus increase CTE values.

\section{Conclusions}

In this work, novel halogen-free flame-retardant epoxy resins composed of EPN-D with DOPO moiety, HMMM, and n-PF were successfully prepared via an in situ polymerization process. Because of the incorporation of HMMM, the obtained thermosets exhibited high $T_{g}$ s, excellent thermal stability, and enhanced the flame retardancy with a high LOI value beyond 45.7. Furthermore, all EPN-D/ HMMM/n-PF thermosets could achieve UL-94 V-0 grade without any drippings, which can be attributed to the positive phosphorous-nitrogen synergistic effect on flame retardancy. With these outstanding properties and the absence of a halogen element, such halogen-free epoxy thermosets can be potentially used as the advanced electrical/electronic materials.

\section{Acknowledgements}

The authors are grateful for the support of China Postdoctoral Science Foundation (Grant number: 20060400339). 


\section{References}

[1] Derouet D., Morvan F., Bross J. C.: Chemical modification of epoxy resins by dialkyl(or aryl) phosphates: evaluation of fire behavior and thermal stability. Journal of Applied Polymer Science, 62, 1855-1868 (1996).

DOI: $10.1002 /(\mathrm{SICI}) 1097-4628(19961212) 62: 11$ $\leq 1855::$ AID-APP10>3.0.CO;2-Y

[2] Camino G., Costa L., Martinasso G.: Intumescent fireretardant systems. Polymer Degradation and Stability, 23, 359-376 (1989). DOI: $10.1016 / 0141-3910(89) 90058-X$

[3] Lu S-Y., Hamerton I.: Recent developments in the chemistry of halogen-free flame retardant polymers. Progress in Polymer Science, 27, 1661-1712 (2002). DOI: 10.1016/S0079-6700(02)00018-7

[4] Liu Y. L.: Epoxy resins from novel monomers with a bis-(9,10-dihydro-9-oxa-10-oxide-10-phosphaphenanthrene-10-yl-) substituent. Journal of Polymer Science Part A: Polymer Chemistry, 40, 359-368 (2002). DOI: $10.1002 /$ pola.10125

[5] Liu Y-L., Wu C-S., Chiu Y-S., Ho W-H.: Preparation, thermal properties, and flame retardance of epoxy-silica hybrid resins. Journal of Polymer Science Part A: Polymer Chemistry, 41, 2354-2367 (2003).

DOI: $10.1002 /$ pola. 10778

[6] Chiu Y-S., Liu Y-L., Wei W-L., Chen W-Y.: Using diethylphosphites as thermally latent curing agents for epoxy compounds. Journal of Polymer Science Part A: Polymer Chemistry, 41, 432-440 (2003).

DOI: $10.1002 /$ pola. 10578

[7] Liu Y-L., Tsai S-H.: Synthesis and properties of new organosoluble aromatic polyamides with cyclic bulky groups containing phosphorus. Polymer, 43, 57575762 (2002).

DOI: $\underline{\text { 10.1016/S0032-3861(02)00473-1 }}$

[8] Liu Y. L., Wu C. S., Hsu K. Y., Chang T. C.: Flameretardant epoxy resins from $o$-cresol novolac epoxy cured with a phosphorus-containing aralkyl novolac. Journal of Polymer Science Part A: Polymer Chemistry, 40, 2329-2339 (2002).

DOI: $10.1002 /$ pola. 10320

[9] Liu Y. L., Chang G. P., Wu C. S.: Halogen-free flame retardant epoxy resins from hybrids of phosphorus- or silicon-containing epoxies with an amine resin. Journal of Applied Polymer Science, 102, 1071-1077 (2006).

DOI: 10.1002/app.24247

[10] Liu Y-L., Chen Y-J.: Novel thermosetting resins based on 4-(N-maleimidophenyl) glycidylether: II. Bismaleimides and polybismaleimides. Polymer, 45, 1797-1804 (2004).

DOI: 10.1016/j.polymer.2004.01.001

[11] Wu C-S., Liu Y-L.: Preparation and properties of epoxy/amine hybrid resins from in situ polymerization. Journal of Polymer Science Part A: Polymer Chemistry, 42, 1868-1875 (2004).

DOI: $10.1002 /$ pola.20031
[12] Chiang C-L., Ma C-C. M.: Synthesis, characterization and thermal properties of novel epoxy containing silicon and phosphorus nanocomposites by sol-gel method. European Polymer Journal, 38, 2219-2224 (2002).

DOI: $10.1016 / \mathrm{S} 0014-3057(02) 00123-4$

[13] Wu C. S., Liu Y. L., Chiu Y-S.: Synthesis and characterization of new organosoluble polyaspartimides containing phosphorus. Polymer, 43, 1773-1779 (2002). DOI: $10.1016 / \mathrm{S} 0032-3861(01) 00751-0$

[14] Shieh J-Y., Wang C-S.: Synthesis of novel flame retardant epoxy hardeners and properties of cured products. Polymer, 42, 7617-7625 (2001). DOI: $10.1016 / \mathrm{S} 0032-3861(01) 00257-9$

[15] Tarek A., Hajime T., Tsutomu T.: Novel organic-inorganic hybrids prepared from polybenzoxazine and titania using sol-gel process. Polymer, 45, 7903-7910 (2004).

DOI: 10.1016/j.polymer.2004.09.022

[16] Zhang X. H., Wan H. M., Min Y. Q., Fang Z., Qi G. R.: Synthesis and thermal properties of a novel nitrogen-containing epoxy resin. Chinese Chemical Letters, 16, 547-550 (2005).

[17] Zhang X. H., Wan H. M., Min Y. Q., Qi G. R.: Novel nitrogen-containing epoxy resin. I. Synthetic kinetics. Journal of Applied Polymer Science, 96, 723-731 (2005). DOI: $10.1002 / a p p .21519$

[18] Zhang X. H., Min Y. Q., Wan H. M., Qi G. R.: Novel nitrogen-containing epoxy resin. II. Cure kinetics by differential scanning calorimetry. Journal of Applied Polymer Science, 100, 3483-3489 (2006). DOI: $10.1002 / a p p .23146$

[19] Zhang X. H., Chen S., Min Y. Q., Qi G. R.: Synthesis of novel bisphenol containing phthalazinone and azomethine moieties and thermal properties of cured diamine/bisphenol/DGEBA polymers. Polymer, 47, 1785-1795 (2006). DOI: $10.1016 /$ j.polymer.2006.01.075

[20] Min Y. Q., Zhang X. H., Zhao H., Qia G. R.: Synthesis of 2,4,6-tri (hydroxylphenylmethylamino)-s-triazine and its curing behavior and mechanism with DGEBA. Acta Polymerica Sinica, 7, 855-859 (2006).

[21] Zhang X. H., Chen S., Chen T., Sun X. K., Liu F., Qi G. R.: Synthesis of a soluble azomethine-containing bisphenol and the properties of its modified epoxy thermosets. Journal of Applied Polymer Science, 106, 1632-1639 (2007). DOI: 10.1002/app.26712

[22] Zhang X-H., Liu F., Chen S., Qi G-R.: Novel flame retardant thermosets from nitrogen-containing and phosphorus-containing epoxy resins cured with dicyandiamide. Journal of Applied Polymer Science, 106, 2391-2397 (2007). DOI: $10.1002 / a p p .26698$ 
[23] Zhang X., Zhou B., Sun X., Qi G.: Preparation and properties of epoxy/phenol formaldehyde novolac/ hexakis (methoxymethyl) melamine hybrid resins from in situ polymerization. Journal of Applied Polymer Science, 110, 4084-4092 (2008).

DOI: 10.1002/app.29016

[24] Zhang X. H., Huang L. H., Chen S., Qi G. R.: Improvement of thermal properties and flame retardancy of epoxy-amine thermosets by introducing bisphenol containing azomethine moiety. Express Polymer Letters, 1, 326-332 (2007).

DOI: $10.3144 /$ expresspolymlett.2007.46

[25] Shau M-D., Wang T-S.: Syntheses, structure, reactivity, and thermal properties of new cyclic phosphine oxide epoxy resins cured by diamines. Journal of Polymer Science Part A: Polymer Chemistry, 34, 387396 (1996).

DOI: $10.1002 /($ SICI) 1099-0518(199602)34:3<387:: AID-POLA7>3.0.CO;2-R

[26] Espinosa M. A., Galià M., Càdiz V.: Novel flameretardant thermosets: Phosphine oxide-containing diglycidylether as curing agent of phenolic novolac resins. Journal of Polymer Science Part A: Polymer Chemistry, 42, 3516-3526 (2004).

DOI: $10.1002 /$ pola.20220

[27] Jeng R-J., Shau S-M., Lin J-J., Su W-C., Chiu Y-S.: Flame retardant epoxy polymers based on all phosphorus-containing components. European Polymer Journal, 38, 683-693 (2002). DOI: $\underline{10.1016 / \mathrm{S} 0014-3057(01) 00246-4}$
[28] Levchik S. V., Weil E. D.: Thermal decomposition, combustion and flame-retardancy of epoxy resins- A review of the recent literature. Polymer International, 53, 1901-1929 (2004).

DOI: $10.1002 /$ pi.1473

[29] Iji M., Kiuchi Y.: Self-extinguishing epoxy molding compound with no flame-retarding additives for electronic components. Journal of Materials Science: Materials in Electronics, 12, 715-723 (2001).

[30] Shieh J-Y., Wang C-S.: Effect of the organophosphate structure on the physical and flame-retardant properties of an epoxy resin. Journal of Polymer Science Part A: Polymer Chemistry, 40, 369-378 (2002). DOI: $10.1002 /$ pola.10121

[31] Hong X., Xiao S., Chen Q., Liu H., Chen J., Li W., Chen M., Chen L.: Studies on hybrid polymesization of hexamethoxymethyl melamine-polyol-acrylate. Acta Polymerica Sinica, 3, 265-270 (2002).

[32] Hsiue G-H., Lee R-H., Jeng R-J.: Organic sol-gel materials for second-order nonlinear optics based on melamines. Journal of Polymer Science Part A: Polymer Chemistry, 37, 2503-2510 (1999).

DOI: $10.1002 /($ SICI) 1099-0518(19990715)37:14 $\leq 2503:$ :AID-POLA24>3.0.CO;2-\#

[33] van Krevelen D. W.: Some basic aspects of flame resistance of polymeric materials. Polymer, 16, 615620 (1975).

DOI: $10.1016 / 0032-3861(75) 90157-3$ 